\title{
COMPARATIVE ANALYSIS OF HYPERFRACTIONATED RADIOTHERAPY VERSUS CONVENTIONAL RADIOTHERAPY IN CARCINOMA CERVIX
}

\author{
N. V. Kalaiyarasi ${ }^{1}$, R. Giridharan ${ }^{2}$
}

${ }_{1}^{1}$ Professor and HOD, Department of Radiation Oncology, RGGGH, Madras Medical College, Chennai.

${ }^{2}$ Professor, Department of Radiation Oncology, RGGGH, Madras Medical College, Chennai.

\begin{abstract}
\section{BACKGROUND}

Cervical cancer is the most common gynaecological malignancy in women for which Concurrent chemoradiation followed by brachytherapy showed established benefits in both organ preservation and survival. The rationale behind hyper-fractionation is that the therapeutic ratio can be improved by increasing the number of fractions and total dose without exceeding the tolerance of late-reacting normal tissues.

Aims- 1 . To assess the feasibility of hyperfractionated schedule in squamous cell carcinoma of uterine cervix. 2 . To assess the response and acute toxicity of hyperfractionated schedule and compare with conventional fractionation.
\end{abstract}

\section{MATERIALS AND METHODS}

50 patients in the age group of 30 to 60 years with biopsy-proven squamous cell carcinoma of the uterine cervix of stage IIB and IIIB who visited the Department of radiotherapy, MMC \& RGGGH from 2002 to 2004 were included - 25 patients in control arm: conventional EBRT 50 Gy (200 cGy/\# in 25 fractions) + LDR and 25 in trial arm: hyperfractionated EBRT 57.6 Gy (1.2 Gy/\# in 48 fractions - 2\#/day separated by 6 hours over 24 days) + LDR. LDR dose delivered was 26 Gy ( $<0.4$ Gy/hr over 1-3 days) in both arms. Response was assessed both clinically and radiologically, 6 weeks after the completion of treatment. Response was assessed using RECIST criteria version 1.1. Toxicity was assessed using Common Toxicity Criteria version 3.0 and RTOG Morbidity scoring criteria version.

\section{RESULTS}

Complete response was observed in $68 \%$ and $84 \%$ of control and trial arms respectively and was more in patients with $<40$ years of age, haemoglobin less than $11 \mathrm{gm} \%$ and bilateral parametrial involvement. Acute toxicity was more common in the hyperfractionated arm which subsided within 2 weeks of completion of treatment. No grade III or IV acute reactions were observed. The median follow-up duration was 5 years. 16 patients- 9 of hyperfractionated arm and 7 of conventional arm were seen at the end of 5 years and were locoregionally free. At 5 years, DFS was $43.75 \%$ for conventional and $56.25 \%$ for hyperfractionation. Late toxicity observed during follow-up included telangiectasia (3 patients), subcutaneous fibrosis ( 2 patients), proctitis (1 patient) and stenosis (3 patients) was observed.

\section{CONCLUSION}

Hyperfractionated radiotherapy is thus feasible in locally advanced carcinoma cervix with better loco-regional control. Acute morbidity observed with this fractionation schedule is manageable and within acceptable limits.

\section{KEYWORDS}

Radiotherapy, Hyperfractionated Radiotherapy, Carcinoma Cervix, Oncology.

HOW TO CITE THIS ARTICLE: Kalaiyarasi NV, Giridharan R. Comparative analysis of hyperfractionated radiotherapy versus conventional radiotherapy in carcinoma cervix. J. Evolution Med. Dent. Sci. 2017;6(3):171-175, DOI: 10.14260/Jemds/2017/42

\section{BACKGROUND}

Cervical cancer is the most common gynaecological malignancy in women. The main treatment for locally advanced cervical cancers is Concurrent chemoradiation followed by brachytherapy with established benefits in both organ preservation and survival.1,2,3,4,5 Radiotherapy is aimed at controlling the primary tumour, while chemotherapy can also be used to eradicate distant metastases. 4

Financial or Other, Competing Interest: None.

Submission 25-11-2016, Peer Review 28-12-2016,

Acceptance 04-01-2017, Published 09-01-2017.

Corresponding Author:

Dr. N. V. Kalaiyarasi,

Professor and $H O D$,

Department of Radiation Oncology,

RGGGH, Madras Medical College, Chennai.

E-mail:dr.kalaiyarasi203@gmail.com

DOI: $10.14260 /$ jemds $/ 2017 / 42$
Several randomized studies showed that Platinum based chemotherapy along with radiation results in $12 \%$ benefit in overall survival and progression- free survival and improved tumour control and $30-50 \%$ reduction in deaths when compared to radiation therapy alone.6,7,8,9,10,11 Altered fractionation schedules have shown significant benefit in head and neck cancers.12 The following study is a comparative study to establish the benefits and feasibility of hyperfractionation in carcinoma cervix. The rationale behind hyper-fractionation is that the therapeutic ratio can be improved by increasing the total dose without exceeding the tolerance of late reacting normal tissues. ${ }^{12,13}$ Fraction size is the most important factor in determining late reactions. Since the fraction size is reduced in hyper-fractionation, the late reactions can be significantly reduced in this protocol. ${ }^{12}$ The rationale of intracavitary brachytherapy forms a major part of concurrent chemoradiation for locally advanced cervical cancers. The total dose to point A depends on the stage, at least 85 Gy for IIIB. 7 


\section{Aim of the Study}

1. To assess the feasibility of hyperfractionated schedule in squamous cell carcinoma of uterine cervix.

2. To assess the locoregional control without increasing the late complications.

3. To assess the response and acute toxicity of hyperfractionated schedule.

4. To compare the response with conventional radiotherapy.

\section{MATERIALS AND METHODS}

The present study was carried out in Department of Radiation Oncology, Madras Medical College. In this study 50 patients in the age group of 30 to 60 years who visited outpatient department from 2002 to 2004 were assigned to arm $\mathrm{A}$ and arm $\mathrm{B}$ by computer generated random permuted blocks values.

Control Arm A- 25 patients- to receive conventional external beam radiation therapy followed by ICCA LDR brachytherapy.

Trial Arm B- 25 patients- to receive hyperfractionated external beam radiation therapy followed by ICCA LDR brachytherapy.

\section{Inclusion Criteria}

1. Age less than 60 years.

2. Multiparous.

3. Performance status KPS $>70$.

4. $\mathrm{Hb}>10 \mathrm{gm} \%$.

5. Stage IIB, IIIA, IIIB.

6. Histology- keratinizing or non-keratinizing squamous cell carcinoma.

7. Renal parameters normal. Creatinine clearance $>80 \mathrm{ml} / \mathrm{min}$.

\section{Exclusion Criteria}

1. $\mathrm{Hb}<10 \mathrm{gm} \%$.

2. Age $>60$ years.

3. Hypertension, Diabetes, Tuberculosis.

4. Previous surgery, Previous RT.

5. Renal parameters abnormal.

6. Pregnancy, other malignancy.

7. Lack of informed consent.

\section{Pre- Treatment Evaluation}

1. Thorough history including menstrual, marital and socioeconomic status.

2. Careful per vaginal and per rectal examination was done to assess extent of tumour.

3. Laboratory investigations including.

a. Complete Haemogram.

b. Blood chemistry with blood urea, sugar and serum creatinine was done.

c. Urine Routine- albumin, sugar, microscopy.

d. Biopsy and Histopathological examination.

4. Radiological Investigations- Chest x-ray, USG Abdomen, IVU.

5. Cystoscopy and Proctoscopy.

6. ELISA to rule out HIV.

7. MRI abdomen- contrast enhanced preferable.

\begin{tabular}{|c|c|c|}
\hline ARMS & $\begin{array}{c}\text { A: Control- } \\
\text { Conventional }\end{array}$ & $\begin{array}{c}\text { B: Trial- } \\
\text { Hyperfractionation }\end{array}$ \\
\hline Total Dose & $50 \mathrm{~Gy}$ & $57.6 \mathrm{~Gy}$ \\
\hline Daily Dose & $200 \mathrm{cGy}$ & $240 \mathrm{cGy}$ \\
\hline Dose per Fraction & $200 \mathrm{cGy}$ & $120 \mathrm{cGy}$ \\
\hline Total No. Fractions & 25 & 48 \\
\hline Total Duration & 5 Weeks & 4.4 Weeks \\
\hline \multicolumn{3}{|c|}{ Treatment protocol } \\
\hline
\end{tabular}

Simulation was done using orthogonal $\mathrm{x}$-rays for both external beam radiation and brachytherapy. In trial arm, a total dose of 57.6 Gy was delivered in $1.2 \mathrm{~Gy} / \#$, twice daily with a gap of atleast 6 hours in between, five days a week for 5 weeks. External Beam Radiation Therapy was given using Cobalt 60 teletherapy machine (Theatron phoenix). A pair of opposing AP / PA portals was used for EBRT. Four Field box technique was used in patients with field separation more than $20 \mathrm{cms}$. LDR Brachytherapy was delivered using CESIUM 137 under epidural anaesthesia with $2 \%$ lignocaine. By intracavitary application, another 26 Gy was delivered to Point $\mathrm{A}$ at a dose rate $<0.4 \mathrm{cGy} / \mathrm{hr}$ over a maximum of 65 hours (2.7 days).

Total dose to Point A - 76 Gy.

Point B - 60 Gy.

Bladder - Less than $75 \mathrm{~Gy}$.

Rectum - Less than 67.5 Gy.

Chemotherapy - Weekly Cisplatin $40 \mathrm{mg} / \mathrm{m}^{2}$ for 5 weeks during EBRT in arm A only.

All 50 patients were available for the final analysis. Average total treatment time was 54 days. Gaps during treatment were mainly observed due to low WBC and/or platelet count or ant grade 3 or 4 reactions.

BED value Gy10 - conventional - 56.5 Gy.

BED value Gy3 - conventional - Bladder - 76 Gy,

Rectum - 76 Gy.

BED value Gy10 - hyperfractionation - $64.5 \mathrm{~Gy}$.

BED value Gy3 - hyperfractionation - Bladder - 74.8 Gy, Rectum - 75.5. Gy.

EQD2- Tumour - conventional - $45.8 \mathrm{~Gy}$.

EQD2- Tumour - hyperfractionation - 53.8 Gy.

\section{Statistical Analysis}

The distribution of the cases to the study and control arm with respect to factors and variables studies were presented using descriptive statistics. The difference in proportion of cases between study and control groups of factors measured on a nominal scale was tested for statistical significance using chi-square test. Yates correction was employed. Odds ratio was employed to study the extent of complete response achieved in the study group compared to control group. Fischer s exact probability test was used whenever zero frequencies are encountered. Student $t$ test is used whenever the factors studied are measured on interval scale.

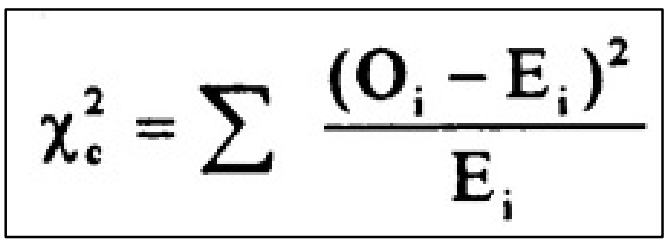


The subscript " $c$ " is the degree of freedom. " $O$ " is your observed value and $E$ is your expected value. $P$ value was calculated. If less than 0.05 , then it is significant. Statistical analysis was done using Window 10 Excel.

\section{Response Evaluation}

Tumour response was evaluated 6 weeks after completion of radiation clinically and CT scan/MRI- Abdomen and pelvis using RECIST criteria version 1.1.

Complete Response- No clinically detectable lesion.

Partial Response- 50\% regression of measurable tumour. No tumour area shows any progression. No new area of lesion made out.

Static Response- No change in tumour size. No tumour area shows any progression. No new area of lesion made out.

Progression- Increase in tumour size with treatment by $25 \%$ or appearance of new lesions or tumour induced death.

\section{Toxicity}

Complete blood count and biochemistry was performed on a weekly basis. Radiation induced toxicity was graded using Common Toxicity Criteria version 3.0 and RTOG acute radiation morbidity scoring criteria. In the case of WBC less than $1000 / \mu \mathrm{l}$ or platelets less than $50,000 / \mu \mathrm{l}$ for a period longer than 5 days, or in the case of any severe grade 3 or 4 , radiation therapy was interrupted until recovery.

\section{Follow Up Procedure}

Patients were assessed for disease status 1 month after the end of treatment and every month for 3 months and then once in 3 months for a period of one year. During follow up, a thorough history, physical examination and a complete pelvic examination was done. Patients with residual disease were taken up for salvage surgery. Late toxicities like subcutaneous fibrosis and telangiectasia was observed and recorded during follow up of patients in our OPD.

\section{RESULTS}

\begin{tabular}{|c|c|c|c|}
\hline & & Arm A & Arm B \\
\hline Age & $31-40$ & 12 & 8 \\
\hline & $41-50$ & 8 & 11 \\
\hline & $51-60$ & 5 & 6 \\
\hline KPS & 90 & 8 & 5 \\
\hline & 80 & 13 & 18 \\
\hline & 70 & 4 & 2 \\
\hline Parity & $>5$ & 8 & 7 \\
\hline & 3 to 4 & 12 & 13 \\
\hline & 1 to 2 & 5 & 5 \\
\hline Hb Status & 10 to 11 & 10 & 20 \\
\hline & $11.1-12$ & 14 & 3 \\
\hline Tumour Stage & $>12$ & 1 & 2 \\
\hline & IIB & 14 & 18 \\
\hline & IIIA & - & - \\
\hline Parametrial Involvement & IIIB & 11 & 7 \\
\hline \multicolumn{2}{|c|}{ IIB } & 14 & 18 \\
\hline Patient characteristics & 7 \\
\hline
\end{tabular}

The patient characteristics were thus and was comparable.
At the end of 50 Gy and 57.6 Gy in control and trial arms respectively, all patients were clinically examined for response. The overall response was $100 \%$. None of the patient showed evidence of progression or static disease. However, the number of complete responders and partial responders varied in the 2 arms shown in following tables:

\begin{tabular}{|c|c|c|c|c|c|}
\hline Stage & $\begin{array}{c}\text { No. of } \\
\text { PTS }\end{array}$ & $\begin{array}{c}\text { CR } \\
\text { Number }\end{array}$ & CR \% & $\begin{array}{c}\text { PR } \\
\text { Number }\end{array}$ & PR \% \\
\hline II B & 14 & 6 & 42 & 8 & 57 \\
\hline IIIB & 11 & 4 & 36 & 7 & 63 \\
\hline Total & $\mathbf{2 5}$ & $\mathbf{1 0}$ & $\mathbf{4 0}$ & $\mathbf{1 5}$ & $\mathbf{6 0}$ \\
\hline \multicolumn{7}{|c|}{ Results of control ARM } \\
\hline
\end{tabular}

\begin{tabular}{|c|c|c|c|c|c|}
\hline Stage & $\begin{array}{c}\text { No. of } \\
\text { PTS }\end{array}$ & $\begin{array}{c}\text { CR } \\
\text { Number }\end{array}$ & CR \% & $\begin{array}{c}\text { PR } \\
\text { Number }\end{array}$ & PR \% \\
\hline II B & 18 & 13 & 72 & 6 & 33 \\
\hline III B & 7 & 5 & 71 & 1 & 14 \\
\hline Total & $\mathbf{2 5}$ & $\mathbf{1 8}$ & $\mathbf{7 2}$ & $\mathbf{7}$ & $\mathbf{2 8}$ \\
\hline \multicolumn{5}{|c|}{ Results of trial ARM } \\
\hline
\end{tabular}

P Value $>0.01$

\section{Analysis after Brachytherapy}

Analysis of immediate response was done after the end of planned treatment in the respective arms. This was done by clinical and radiological examination.

\begin{tabular}{|c|c|c|c|c|c|}
\hline Stage & $\begin{array}{c}\text { No. of } \\
\text { Patients }\end{array}$ & $\begin{array}{c}\text { CR } \\
\text { Number }\end{array}$ & CR \% & $\begin{array}{c}\text { PR } \\
\text { Number }\end{array}$ & PR \% \\
\hline II B & 14 & 10 & 71 & 4 & 28 \\
\hline IIIB & 11 & 7 & 63 & 4 & 36 \\
\hline Total & $\mathbf{2 5}$ & $\mathbf{1 7}$ & $\mathbf{6 8}$ & $\mathbf{8}$ & $\mathbf{3 2}$ \\
\hline \multicolumn{6}{|c|}{ Results of control ARM } \\
\hline
\end{tabular}

\begin{tabular}{|c|c|c|c|c|c|}
\hline Stage & $\begin{array}{c}\text { No of } \\
\text { Patients }\end{array}$ & $\begin{array}{c}\text { CR } \\
\text { Number }\end{array}$ & CR \% & $\begin{array}{c}\text { PR } \\
\text { Number }\end{array}$ & PR \% \\
\hline II B & 18 & 16 & 88 & 2 & 11 \\
\hline III B & 7 & 5 & 71 & 2 & 28 \\
\hline Total & $\mathbf{2 5}$ & $\mathbf{2 1}$ & $\mathbf{8 4}$ & $\mathbf{4}$ & $\mathbf{1 6}$ \\
\hline \multicolumn{6}{|c|}{ Results of trial ARM } \\
\hline
\end{tabular}

\begin{tabular}{|c|c|c|c|c|}
\hline \multirow{2}{*}{ Stage } & \multicolumn{2}{|c|}{ ARM A } & \multicolumn{2}{c|}{ ARM B } \\
\cline { 2 - 5 } & CR\% & PR\% & CR\% & PR\% \\
\hline IIB & 71 & 28 & 88 & 11 \\
\hline IIIB & 63 & 36 & 71 & 28 \\
\hline Total & 68 & 32 & 84 & 16 \\
\hline \multicolumn{4}{|c|}{ Comparative analysis } \\
\hline
\end{tabular}

P Value 0.01- Statistically Significant

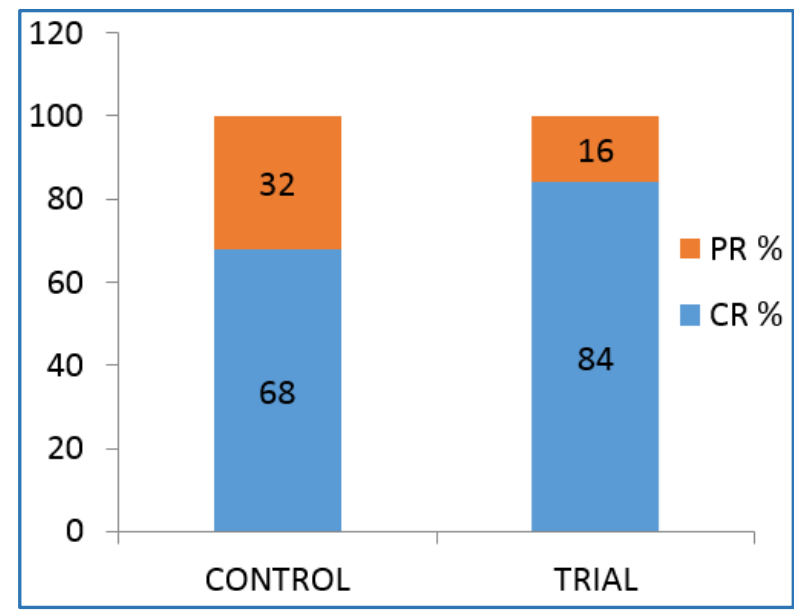

Immediate response rates at the end of treatment 


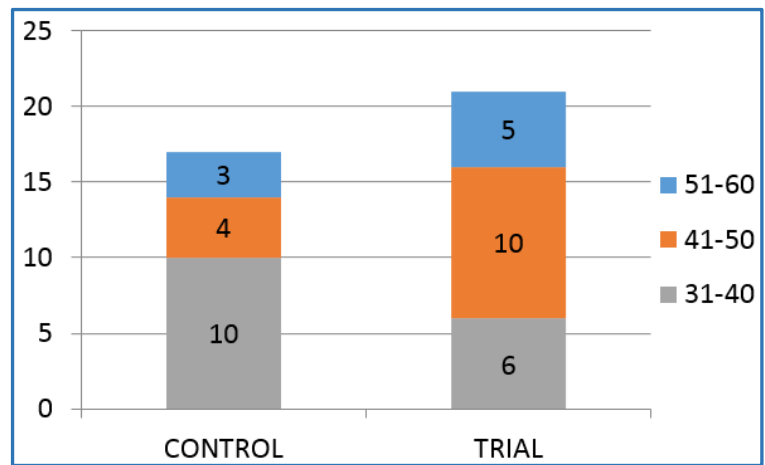

Complete response vs age of patient

$P$ value- 0.002 - Statistically Significant

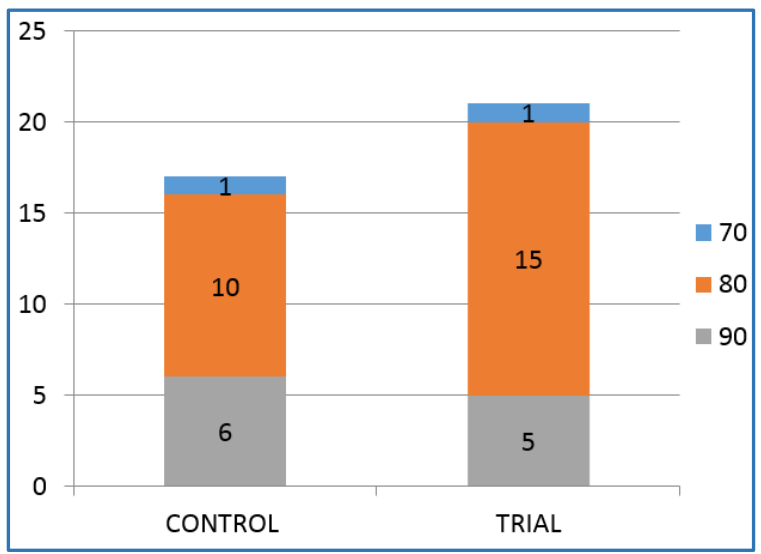

Complete response vs performance status

P value- 0.26 - Not Statistically Significant

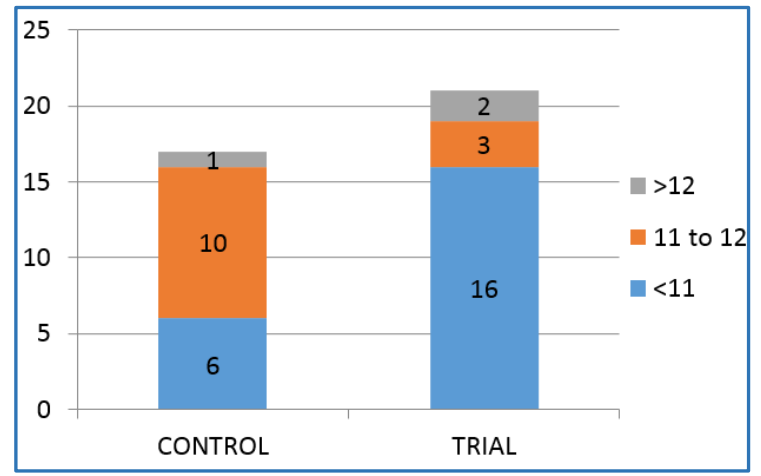

Complete response vs hemoglobin status

P value-1.25- Not Statistically Significant

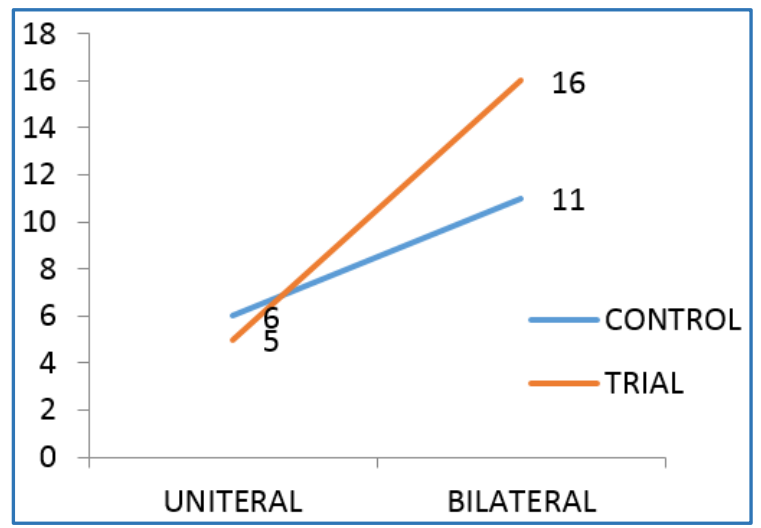

Complete response vs parametrial involvement

P value- $0.11-$ not statistically significant

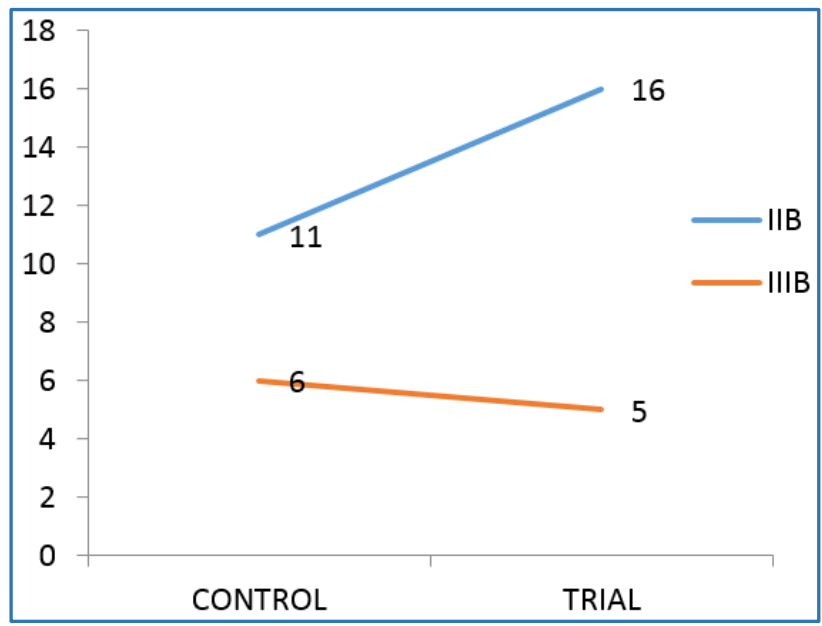

Complete response vs tumour stage

$P$ value- 0.11 - not statistically significant

Analysis of Partial Responders in Control ARM

Higher rates of partial response was seen in

1. Age $<60$ Yrs. (PR 40\%).

2. Performance status 70 (PR 75\%).

3. Hb status $10-11 \mathrm{~g} \%$ (PR 40\%).

4. HPE keratinizing type (PR 36\%).

5. Parametrial disease bilateral (PR 35\%).

Analysis of Partial Responders in Trial ARM

Higher rates of partial response was seen in,

1. Age $<40$ yrs. (PR 25\%).

2. Performance status 70 (PR 50\%).

3. Hb status $<11 \mathrm{~g} \%$ (PR 25\%).

4. Parametrial disease bilateral (PR 20\%).

5. Stage IIIB (PR 29\%).

These partial responders were subjected to either adjuvant chemotherapy or surgery depending on the extent of residue present.

\begin{tabular}{|c|c|c|c|}
\hline \multicolumn{2}{|c|}{ BED Value } & $\begin{array}{c}\text { Conventional } \\
\text { ARM A }\end{array}$ & $\begin{array}{c}\text { Hyperfractionation } \\
\text { ARM B }\end{array}$ \\
\hline \multicolumn{2}{|r|}{ Gy10 } & $56.5 \mathrm{~Gy}$ & $64.5 \mathrm{~Gy}$ \\
\hline \multirow{2}{*}{ Gy3 } & Bladder & 76 Gy & $74.8 \mathrm{~Gy}$ \\
\hline & Rectum & $76 \mathrm{~Gy}$ & $75.5 \mathrm{~Gy}$ \\
\hline \multicolumn{2}{|r|}{ EQD2 } & $45.8 \mathrm{~Gy}$ & $53.8 \mathrm{~Gy}$ \\
\hline
\end{tabular}

\begin{tabular}{|c|c|c|c|c|}
\hline $\begin{array}{c}\text { Acute } \\
\text { Effects }\end{array}$ & $\begin{array}{c}\text { RTOG } \\
\text { Grade }\end{array}$ & $\begin{array}{c}\text { Control } \\
\text { ARM }\end{array}$ & $\begin{array}{c}\text { Trial } \\
\text { ARM }\end{array}$ & P Value \\
\hline \multirow{2}{*}{ Skin } & Gr-1 & $\begin{array}{c}5(20 \%) \\
2(8 \%)\end{array}$ & $\begin{array}{c}10(40 \%) \\
6(24 \%)\end{array}$ & 0.0003 \\
\hline \multirow{2}{*}{ Rectum } & Gr-1 & $\begin{array}{c}4(16 \%) \\
2(8 \%)\end{array}$ & $\begin{array}{c}10(40 \%) \\
4(16 \%)\end{array}$ & 0.0009 \\
\hline Gladder & Gr-1 & $4(16 \%)$ & $8(32 \%)$ & - \\
\hline \multicolumn{5}{|c|}{ Toxicities / morbidities observed } \\
\hline
\end{tabular}

The above showed higher toxicities in the hyperfractionation arm and this was statistically significant. There were no treatment dropouts or treatment related deaths during this study.

The median follow up duration was 5 years. 16 patients 9 of the hyperfractionated arm and 7 of the conventional arm were seen at last follow up and were locoregionally free of disease. The rest of the patients were lost to follow up. 


\begin{tabular}{|c|c|c|c|c|}
\hline & $\begin{array}{c}\text { No. of } \\
\text { Patients on } \\
\text { follow } \\
\text { up at } \\
\text { End of 5 } \\
\text { Years }\end{array}$ & $\begin{array}{c}\text { Complete } \\
\text { Response }\end{array}$ & $\begin{array}{c}\text { Partial } \\
\text { Response }\end{array}$ & $\begin{array}{c}\text { Progressive } \\
\text { Disease }\end{array}$ \\
\hline $\begin{array}{c}\text { Conventional- } \\
\text { Arm A }\end{array}$ & $\begin{array}{c}7-6 \text { (IIB) } \\
1 \text { (III) }\end{array}$ & $\begin{array}{c}7 \\
(100 \%)\end{array}$ & - & - \\
\hline $\begin{array}{c}\text { Hyper- } \\
\text { fractionation- } \\
\text { Arm B }\end{array}$ & $\begin{array}{c}9-8 \text { (IIB) } \\
1 \text { (III) }\end{array}$ & $\begin{array}{c}9 \\
(100 \%)\end{array}$ & - & - \\
\hline
\end{tabular}

\begin{tabular}{|c|c|c|}
\hline Late toxicity & $\begin{array}{c}\text { Conventional } \\
\text { (7 Patients) }\end{array}$ & $\begin{array}{c}\text { Hyperfractionation } \\
\text { (9 Patients) }\end{array}$ \\
\hline Telangiectasia & 1 & 2 \\
\hline $\begin{array}{c}\text { Subcutaneous } \\
\text { Fibrosis }\end{array}$ & 2 & - \\
\hline Proctitis & 1 & - \\
\hline Stenosis & 2 & 1 \\
\hline \multicolumn{2}{|c|}{ Late toxicity observed during follow up } \\
\hline
\end{tabular}

Late toxicity observed in the hyperfractionation arm was less as expected. $\mathrm{P}$ value obtained was 0.21 which is not statistically significant. Survival analysis showed that at 5 years, disease free survival $43.75 \%$ in the conventional arm and $56.25 \%$ in the hyperfractionation arm.

\section{DISCUSSION}

Carcinoma cervix is the commonest malignancy affecting females of developing countries. Locoregional failure is the primary cause of decreased survival due to parametrial involvement. The $5 \mathrm{yr}$ survival rates for stage IIB and IIIB with bilateral parametrial involvement is $58 \%$ and $28 \%$ respectively. ABS recommends 60 Gy dose to the parametrium for optimum response. By giving hyperfractionated radiotherapy dose to the parametrium is increased to 57.6 Gy and the tumour volume is reduced further making brachytherapy feasible.

In this trial after 57.6 Gy of EBRT in hyperfractionation, out of 25 patients, 18 patients attained complete response. The complete responders in trial arm included $4(100 \%)$ with unilateral disease and $7(50 \%)$ with bilateral parametrial involvement.

In our trial, after hyperfractionated external beam radiotherapy, brachytherapy was given using LDR. LDR brachytherapy was selected because acute toxicities due to hyperfractionated EBRT compared to conventional RT was high and is HDR was selected that will also add to the toxicity so LDR was chosen.

The toxicities and morbidities observed were minimal. There were no treatment dropouts or treatment related deaths during this study.

In this trial, acute reactions were more with hyperfractionated RT. No grade III or IV complications were observed. All acute reactions subsided within 2 weeks of completion of treatment. No rest period was required in between. Good loco-regional control was achieved.

\section{CONCLUSION}

1. Hyper-fractionated radiotherapy is feasible in locally advanced carcinoma uterine cervix.

2. Acute morbidity is within acceptable limits.
3. Late toxicity was observed in both conventional and hyperfractionation arm and was less in altered fractionation arm.

\section{REFERENCES}

[1] Blake PR, Branson AN, Lambert HE. Combined radiotherapy and chemotherapy for advanced carcinoma of the cervix. Clinical radiology 1986;37(5):465-9.

[2] Runowicz CD, Wadler S, Rodriguez-Rodriguez L, et al. Concurrent cisplatin and radiotherapy in locally advanced cervical carcinoma. Gynecol Oncol 1989;34:395-401.

[3] Rose PG, Bundy BN, Watkins EB, et al. Concurrent cisplatin-based radiotherapy and chemotherapy for locally advanced cervical cancer. $N$ Engl J Med 1999;340(15):1144-53.

[4] Rose. Role of chemo radiation in locally advanced cancer cervix. Gyn oncology 1990;38:446-51.

[5] Greven KM, Levenback C, Chao CKS, et al. Gynaecology cancer working group. Int journal oncology, biology and physics 2001;51(3 Suppl 2):589.

[6] Tattersall. Randomized trial comparing cisplatin based chemotherapy vs radiotherapy alone in locally advanced cervical cancer. Int Jou of Gynaec Cancer 1993;2:244-51.

[7] Fields AL, Anderson PS, Goldberg GL, et al. Mature results of a phase II trial of concomitant cisplatin/pelvic radiotherapy for locally advanced squamous cell carcinoma of the cervix. Gynaec oncology 1996;61(3):416-22.

[8] Twiggs LB, Potish RA, McIntyre S, et al. Concurrent weekly cis-platinum and radiotherapy in advanced cervical cancer: a preliminary dose escalating toxicity study. Gynecol oncol 1986;24(2):143-8.

[9] Potish, Roger A, Twiggs L, Effect of cis-platinum on tolerance to radiation therapy in advanced cervical cancer. American Journal of clinical radiology 1986;9(5):387-91.

[10] Morris M, Eifel PJ, Lu J, et al. Pelvic radiation with concurrent chemotherapy compared with pelvic and para-aortic radiation for high-risk cervical cancer. NEJM 1999;340(15):1137-43.

[11] Whitney CW, Sause W, Bundy BN, et al. Randomized comparison of fluorouracil plus cisplatin versus hydroxyurea as an adjunct to radiation therapy in stage iib-iva carcinoma of the cervix with negative para-aortic lymph nodes: a gynecologic oncology group and southwest oncology group study. Journal of clinical oncology 1999;17(5):1339-48.

[12] Komaki R, Pajak TF, Marcial VA, et al. Twice-daily fractionation of external irradiation with brachytherapy in bulky carcinoma of the cervix. Phase I/II study of the radiation therapy oncology group 8805. Cancer 1994;73(10):2619-25.

[13] Grisby PW, Mutch D, Kim RY, et al. Twice daily fractionation of external irradiation with brachytherapy and chemotherapy in carcinoma of cervix with positive para-aortic lymph nodes: phase II study of the radiation therapy oncology group 92-10. Int JR irradiation oncology Bio Physics 1988;41(4):817-22. 